
\title{
25 Research Soure \\ Latent Myofascial Trigger Points Release Therapy for Adult Cough Variant Asthma
}

\section{Qianqian Liu}

Shandong University Qilu Hospital

\section{Wenwen Zhang}

Shandong University Qilu Hospital

\section{Tian Tian}

Shandong University Qilu Hospital

\section{He Bai}

Shandong University Qilu Hospital

\section{Qiya Hu}

Shandong University Qilu Hospital

Feng Qi ( $\sim$ qifeng66321@sina.com )

Shandong University Qilu Hospital https://orcid.org/0000-0002-0272-493X

\section{Research}

Keywords: Cough variant asthma, Latent myofascial trigger points, Autonomic phenomena, Airway hyperresponsiveness, Inflammation, Inhaled corticosteroid

Posted Date: October 5th, 2021

DOl: https://doi.org/10.21203/rs.3.rs-940223/v1

License: (c) (i) This work is licensed under a Creative Commons Attribution 4.0 International License.

Read Full License 


\section{Abstract}

\section{Background:}

Cough variant asthma (CVA) is a chronic inflammatory airway disease characterized by airway hyperresponsiveness (AHR). However, it's precise mechanism is not clear yet. The date show that latent myofascial trigger points (MTrPs) can induce autonomic phenomena, such as over secretion, airway hyper-responsiveness, and so on. Therefore, we assumed that latent MTrPs might disrupt the balance between sympathetic and parasympathetic, which might play an essential role in the etiology of CVA.

\section{Results:}

Recurrence rate was lower in the intervention group than the control group (36w, 5.0\% vs. $34.5 \%$, $P=0.001)$. There were significant between-group differences in change from baseline to 36 weeks in VAS ( $5.80 \pm 1.20$ to $1.70 \pm 1.49$ and $5.53 \pm 1.21$ to $3.18 \pm 2.04$, respectively; $95 \% \mathrm{Cl},-2.00$ to $-1.00 ; P=0.001$ ); ACTscores ( $12.78 \pm 1.86$ to $21.38 \pm 2.65$ and $13.09 \pm 1.97$ to $18.53 \pm 3.00$, respectively; $95 \% \mathrm{Cl}, 2.00$ to 4.00 ; $P<0.001)$; ACQ5-scores $(2.35 \pm 0.86$ to $0.85 \pm 0.55$ and $2.38 \pm 0.50$ to $1.52 \pm 0.62$, respectively; $95 \% \mathrm{Cl},-1.00$ to $-0.40 ; P<0.001)$; AQLQ-scores ( $119.65 \pm 17.55$ to $174.40 \pm 18.22$ and $126.22 \pm 15.58$ to $151.69 \pm 24.04$, respectively; $95 \% \mathrm{Cl}, 14.00$ to $34.00 ; P<0.001)$; Rate of rescue medication used ( $36 \mathrm{w}, 5.0 \%$ vs. $29.1 \%$, $P=0.003)$. Fewer adverse events were founded between the two groups ( $7.5 \%$ vs. $14.5 \%, P=0.462$ ).

\section{Conclusions:}

Compared with budesonide-formoterol plus montelukast therapy, latent MTrPs injection therapy provided a long-acting, practical, short treatment course and safety methods for CVA. The findings indicated that latent MTrPs might play a vital role in the pathogenesis of CVA.

Clinical Trials Registration: Chinese Clinical Trial Registry, ChiCTR2100044079. Registered 9 March 2021, http://www.chictr.org.cn/index.aspx

\section{Background}

Cough variant asthma (CVA) is an atypical form of asthma with cough as the sole presenting symptom, a worldwide common chronic airway inflammation disease, influencing $1 \%-18 \%$ of the population in different countries(1). A multicenter prospective observational study shows that about a third of the chronic cough is caused by $\operatorname{CVA}(2,3)$. Nevertheless, the mechanisms responsible for cough reflex hypersensitivity are not fully clear. Guidelines recommend that adults or children with CVA regularly use a low dose of inhaled glucocorticoids as a maintenance treatment to reduce airway inflammation and AHR(4-6). Pharmacogenomics has been indicated that genetic polymorphisms can change the response to bronchodilators in patients with asthma(7). About $5 \%$ of patients with CVA remain poorly controlled despite have used inhaled glucocorticoids or leukotriene-receptor antagonists(8). 
Myofascial trigger points (MTrPs) are defined as hyperirritable spots, usually within a taut band of skeletal muscle, which is painful on palpation and can induce referred pain, motor dysfunction, and autonomic phenomena(9). Whether accompanied by spontaneous pain, MTrPs can be divided into active and latent $\operatorname{MTrPs}(10,11)$. In general, active MTrPs cause clinical pain syndromes. Whereas latent MTrPs can induce non-pain-related symptoms such as depression, anxiety, insomnia, and tinnitus. In addition, latent MTrPs occur in the head and cervical may cause cough, tears, rhinorrhea, salivation, and other autonomic phenomena (12).

The pathophysiologic mechanisms of CVA remain ill-defined; however, chronic inflammation and AHR are considered to play an important role. Our previous experience with CVA patients offered two primary reasons to explain the possible interaction between CVA and latent MTrPs: (1) the palpation of latent MTrPs provoked temporary cough in some patients and (2) the deactivation of latent MTrPs allowed cough improvement or even its disappearance. Consequently, we supposed that inflammation of the latent MTrPs in the head and neck are somewhat correlated to the pathogenesis of CVA.

So far, the scientific literature is inferior impoverished as to the possible influence of latent MTrPs on the origin or persistence of CVA. To investigate the effectiveness and safety of latent MTrPs injection therapy on CVA, we conducted an open-label randomized controlled trial.

\section{Results}

\section{Patients}

Of the 250 patients who were enrolled, after 2 weeks run-in period, 110 patients underwent randomization in a $1: 1.5$ ratio. A total of $90.9 \%(40 / 44)$ of participants in the intervention group and $83.3 \%(55 / 66)$ of those in the control group completed follow-up (Fig. 1). The two groups were similar concerning baseline characteristics $(P>0.05$; Table 1$)$. 
Table 1

Characteristics of the Enrolled Participates at Randomization

\begin{tabular}{|llll|}
\hline Characteristic & $\begin{array}{l}\text { Intervention group } \\
(\mathbf{n}=\mathbf{4 0})\end{array}$ & Control group (n= 55) & P-value \\
\hline Sex, $\mathrm{n}(\%)$ & & & \\
\hline Male & $15(37.5)$ & $22(40.0)$ & 0.805 \\
\hline Female & $25(62.5)$ & $33(60.0)$ & 0.805 \\
\hline Age (Mean \pm SD) & $45.56 \pm 12.04$ & $41.62 \pm 14.06$ & 0.154 \\
\hline Education attainment, $\mathrm{n}(\%)$ & & & \\
\hline Primary school and lower & $3(7.5)$ & $8(14.5)$ & 0.563 \\
\hline Middle and high school & $23(57.5)$ & $30(54.5)$ & 0.563 \\
\hline College and higher & $14(35.0)$ & $17(30.9)$ & 0.563 \\
\hline Cigarette smoking, $\mathrm{n}(\%)$ & & & 0.845 \\
\hline No smoking & $31(77.5)$ & $40(72.1)$ & 0.845 \\
\hline Ever smoking & $7(17.5)$ & $11(7.3)$ & 0.845 \\
\hline Passive smoking & $2(5.0)$ & $4(20.0)$ & 0.208 \\
\hline Family history of CVA, $\mathrm{n}(\%)$ & $4(10.0 \%)$ & $2(3.6 \%)$ & 0.600 \\
\hline ACT score (mean \pm SD) & $12.78 \pm 1.86$ & $13.09 \pm 1.97$ & 0.353 \\
\hline ACQ5 score (mean \pm SD) & $2.35 \pm 0.68$ & $2.37 \pm 0.50$ & 0.339 \\
\hline VAS score (mean \pm SD) & $5.80 \pm 1.20$ & $5.52 \pm 1.21$ & $126.22 \pm 15.58$ \\
\hline AQLQ score (mean \pm SD) & $119.65 \pm 17.55$ & & \\
\hline
\end{tabular}

\section{Primary outcomes}

Overall, 21 of 95 participants (22.1\%) were recurred within 36 weeks: 2 of $44(5 \%)$ in the intervention group vs 19 of $55(34.5 \%)$ in the control group ( $P=0.001$; Table 2$)$. After treatment, the intervention group showed a significant VAS reduction compared to the control group during the overall follow-up period. Improvement in cough symptoms was evident from the first week of treatment and persisted to an endpoint. The results of efficacy analysis are shown in Table 3, Fig. 2A. The VAS at week 1, week2 2, week 4, week 8 , week 12, week 24 , week 36 for intervention and control groups were $1.95 \pm 1.36$ vs. $3.78 \pm 1.45$, $1.48 \pm 1.28$ vs. $3.27 \pm 1.58,1.30 \pm 1.29$ vs. $2.71 \pm 1.72,1.18 \pm 1.28$ vs. $2.11 \pm 1.85,1.23 \pm 1.37$ vs. $2.51 \pm$ $1.94,1.43 \pm 1.48$ vs. $2.85 \pm 2.06$ and $1.70 \pm 1.49$ vs. $3.18 \pm 2.04$, respectively $(P<0.01)$, which has a statistically significant. 
Table 2

Primary outcome of recurrence and secondary outcome of needed for rescue medication

\begin{tabular}{|llll|}
\hline Outcome & Group, No. (\%) & & \\
\cline { 2 - 4 } & Intervention group $(\mathbf{n = 4 0 )}$ & Control group ( $=\mathbf{5 5})$ & Pvalue \\
\hline Primary outcome & $2(5.0 \%)$ & $19(34.5 \%)$ & 0.001 \\
Recurrence within 36 weeks & & & \\
\hline Secondary outcomes & & & 0.462 \\
\hline Adverse events & $3(7.5 \%)$ & $8(14.5 \%)$ & 0.003 \\
\hline Rate of rescue medication use & $2(5.0 \%)$ & $16(29.1 \%)$ & \\
\hline
\end{tabular}


Table 3

Summary of study outcomes

\begin{tabular}{|c|c|c|c|c|c|}
\hline & $\begin{array}{l}\text { Intervention } \\
\text { group }(n=40)\end{array}$ & Control group $(n=55)$ & $95 \% \mathrm{Cl}$ & $Z$ value & $P$-value \\
\hline \multicolumn{6}{|c|}{ Baseline } \\
\hline \multicolumn{6}{|c|}{ Primary outcome } \\
\hline \multirow[t]{2}{*}{ VAS } & $5.80 \pm 1.20$ & $5.52 \pm 1.21$ & 0.001 & -0.957 & 0.339 \\
\hline & & & (0.001 to 1.000$)$ & & \\
\hline \multicolumn{6}{|c|}{ Secondary outcomes } \\
\hline \multirow[t]{2}{*}{ ACQ5 } & $2.35 \pm 0.86$ & $2.38 \pm 0.50$ & -0.200 & -0.929 & 0.353 \\
\hline & & & $(-0.400$ to 0.200$)$ & & \\
\hline \multirow[t]{2}{*}{ ACT } & $12.78 \pm 1.86$ & $13.09 \pm 1.97$ & 0.001 & -0.524 & 0.600 \\
\hline & & & $(-1.000$ to 1.000$)$ & & \\
\hline \multirow[t]{2}{*}{ AQLQ } & $119.65 \pm 17.55$ & $126.22 \pm 15.58$ & -5.00 & -1.381 & 0.167 \\
\hline & & & $(-11.00$ to 2.00$)$ & & \\
\hline \multicolumn{6}{|c|}{ Week 1} \\
\hline \multicolumn{6}{|c|}{ Primary outcome } \\
\hline \multirow[t]{2}{*}{ VAS } & $1.95 \pm 1.36$ & $3.78 \pm 1.45$ & -2.000 & -5.363 & $<0.001$ \\
\hline & & & $(-2.000$ to -1.000$)$ & & \\
\hline \multicolumn{6}{|c|}{ Secondary outcomes } \\
\hline \multirow[t]{2}{*}{ ACQ5 } & $1.00 \pm 0.59$ & $1.85 \pm 0.46$ & -1.000 & -6.138 & $<0.001$ \\
\hline & & & $(-1.200$ to -0.600$)$ & & \\
\hline \multirow[t]{2}{*}{ ACT } & $20.40 \pm 2.95$ & $17.05 \pm 2.32$ & 4.000 & -5.422 & $<0.001$ \\
\hline & & & (3.000 to 5.000$)$ & & \\
\hline \multirow[t]{2}{*}{ AQLQ } & $170.65 \pm 17.21$ & $141.55 \pm 14.60$ & 31.00 & -6.511 & $<0.001$ \\
\hline & & & (24.00 to 37.00$)$ & & \\
\hline \multicolumn{6}{|c|}{ Week 2} \\
\hline Primary & tcomes & & & & \\
\hline
\end{tabular}

Date are present as mean \pm standard deviation 


\begin{tabular}{|c|c|c|c|c|c|}
\hline & $\begin{array}{l}\text { Intervention } \\
\text { group }(n=40)\end{array}$ & Control group $(n=55)$ & $95 \% \mathrm{Cl}$ & $Z$ value & $P$ value \\
\hline \multirow[t]{2}{*}{ VAS } & $1.48 \pm 1.28$ & $3.27 \pm 1.58$ & -2.000 & -5.439 & $<0.001$ \\
\hline & & & $(-2.000$ to -1.000$)$ & & \\
\hline \multicolumn{6}{|c|}{ Secondary outcomes } \\
\hline \multirow[t]{2}{*}{ ACQ5 } & $0.83 \pm 0.44$ & $1.57 \pm 0.49$ & -0.800 & -6.224 & $<0.001$ \\
\hline & & & $(-1.000$ to -0.600$)$ & & \\
\hline \multirow[t]{2}{*}{ ACT } & $21.30 \pm 2.20$ & $18.18 \pm 2.36$ & 3.000 & -5.833 & $<0.001$ \\
\hline & & & (2.000 to 4.000$)$ & & \\
\hline \multirow[t]{2}{*}{ AQLQ } & $174.30 \pm 14.80$ & $149.78 \pm 16.74$ & 25.00 & -6.349 & $<0.001$ \\
\hline & & & (18.00 to 31.00$)$ & & \\
\hline \multicolumn{6}{|c|}{ Week 4} \\
\hline \multicolumn{6}{|c|}{ Primary outcome } \\
\hline \multirow[t]{2}{*}{ VAS } & $1.30 \pm 1.29$ & $2.71 \pm 1.72$ & -1.000 & -4.295 & $<0.001$ \\
\hline & & & $(-2.000$ to -1.000$)$ & & \\
\hline \multicolumn{6}{|c|}{ Secondary outcomes } \\
\hline \multirow[t]{2}{*}{ ACQ5 } & $0.76 \pm 0.42$ & $1.43 \pm 0.51$ & -0.800 & -5.845 & $<0.001$ \\
\hline & & & $(-1.000$ to -0.400$)$ & & \\
\hline \multirow[t]{2}{*}{ ACT } & $21.63 \pm 2.11$ & $18.88 \pm 2.39$ & 3.000 & -5.808 & $<0.001$ \\
\hline & & & (2.000 to 4.000$)$ & & \\
\hline \multirow[t]{2}{*}{ AQLQ } & $176.90 \pm 14.14$ & $154.69 \pm 17.40$ & 22.00 & -6.006 & $<0.001$ \\
\hline & & & (15.00 to 30.00$)$ & & \\
\hline \multicolumn{6}{|c|}{ Week 8} \\
\hline \multicolumn{6}{|c|}{ Primary outcome } \\
\hline \multirow[t]{2}{*}{ VAS } & $1.18 \pm 1.28$ & $2.11 \pm 1.85$ & -1.000 & -2.644 & 0.008 \\
\hline & & & $(-1.000$ to 0.001$)$ & & \\
\hline
\end{tabular}

Date are present as mean \pm standard deviation 


\begin{tabular}{|c|c|c|c|c|c|}
\hline & $\begin{array}{l}\text { Intervention } \\
\text { group }(n=40)\end{array}$ & Control group $(n=55)$ & $95 \% \mathrm{Cl}$ & $Z$ value & $P$ value \\
\hline \multirow[t]{2}{*}{ ACQ5 } & $0.67 \pm 0.43$ & $1.31 \pm 0.51$ & -0.600 & -5.763 & $<0.001$ \\
\hline & & & $(-0.800$ to -0.400$)$ & & \\
\hline \multirow[t]{2}{*}{ ACT } & $22.08 \pm 2.10$ & $19.62 \pm 2.49$ & 2.000 & -5.139 & $<0.001$ \\
\hline & & & (1.000 to 3.000$)$ & & \\
\hline \multirow[t]{2}{*}{ AQLQ } & $179.25 \pm 14.50$ & $159.76 \pm 19.51$ & 18.00 & -5.037 & $<0.001$ \\
\hline & & & (17.00 to 21.00$)$ & & \\
\hline \multicolumn{6}{|c|}{ Week 12} \\
\hline \multicolumn{6}{|c|}{ Primary outcome } \\
\hline \multirow[t]{2}{*}{ VAS } & $1.23 \pm 1.37$ & $2.51 \pm 1.94$ & -1.000 & -3.429 & 0.001 \\
\hline & & & $(-2.000$ to 0.001$)$ & & \\
\hline \multicolumn{6}{|c|}{ Secondary outcomes } \\
\hline \multirow[t]{2}{*}{ ACQ5 } & $0.67 \pm 0.43$ & $1.35 \pm 0.54$ & -0.600 & -6.106 & $<0.001$ \\
\hline & & & $(-0.800$ to -0.400$)$ & & \\
\hline \multirow[t]{2}{*}{ ACT } & $22.13 \pm 2.02$ & $19.31 \pm 2.75$ & 3.000 & -5.415 & $<0.001$ \\
\hline & & & (1.000 to 4.000$)$ & & \\
\hline \multirow[t]{2}{*}{ AQLQ } & $178.58 \pm 14.75$ & $158.53 \pm 21.71$ & 19.00 & -4.464 & $<0.001$ \\
\hline & & & (10.00 to 29.00$)$ & & \\
\hline \multicolumn{6}{|c|}{ Week 24} \\
\hline \multicolumn{6}{|c|}{ Primary outcome } \\
\hline \multirow[t]{2}{*}{ VAS } & $1.43 \pm 1.48$ & $2.85 \pm 2.06$ & -1.000 & -3.469 & 0.001 \\
\hline & & & $(-2.000$ to -1.000$)$ & & \\
\hline \multicolumn{6}{|c|}{ Secondary outcomes } \\
\hline \multirow[t]{2}{*}{ ACQ5 } & $0.78 \pm 0.46$ & $1.47 \pm 0.62$ & -0.800 & -5.143 & $<0.001$ \\
\hline & & & $(-1.000$ to -0.400$)$ & & \\
\hline \multirow[t]{2}{*}{ ACT } & $21.78 \pm 2.28$ & $18.85 \pm 2.90$ & 3.000 & -5.169 & $<0.001$ \\
\hline & & & (2.000 to 4.000 ) & & \\
\hline
\end{tabular}

Date are present as mean \pm standard deviation 


\begin{tabular}{|c|c|c|c|c|c|}
\hline & $\begin{array}{l}\text { Intervention } \\
\text { group }(n=40)\end{array}$ & Control group $(n=55)$ & $95 \% \mathrm{Cl}$ & $Z$ value & $P$-value \\
\hline AQLQ & $176.95 \pm 15.92$ & $154.55 \pm 23.07$ & $\begin{array}{l}22.00 \\
(12.00 \text { to } 33.00)\end{array}$ & -4.653 & $<0.001$ \\
\hline Week 3 & & & & & \\
\hline Primar & tcome & & & & \\
\hline VAS & $1.70 \pm 1.49$ & $3.18 \pm 2.04$ & $\begin{array}{l}-1.000 \\
(-2.000 \text { to }-1.000)\end{array}$ & -3.444 & 0.001 \\
\hline Seconc & outcomes & & & & \\
\hline ACQ5 & $0.85 \pm 0.55$ & $1.52 \pm 0.62$ & $\begin{array}{l}-0.800 \\
(-1.000 \text { to }-0.400)\end{array}$ & -4.867 & $<0.001$ \\
\hline ACT & $21.38 \pm 2.65$ & $18.53 \pm 3.00$ & $\begin{array}{l}3.000 \\
(2.000 \text { to } 4.000)\end{array}$ & -4.286 & $<0.001$ \\
\hline AQLQ & $174.40 \pm 18.22$ & $151.69 \pm 24.04$ & $\begin{array}{l}25.00 \\
(14.00 \text { to } 34.00)\end{array}$ & -4.445 & $<0.001$ \\
\hline
\end{tabular}

A significant improvement in the VAS was also observed in the control group, which begun at week 1 and throughout the study (from $5.53 \pm 1.21$ to $3.18 \pm 2.04, P<0.001$, Table 4,Fig. 3 A).

Table 4

Change from baseline in VAS, ACT, and ACQ5 in Control group

\begin{tabular}{|lllll|}
\hline Time points & VAS & ACT & ACQ5 & \multicolumn{2}{c|}{$P$-value } \\
\hline Baseline & $5.52 \pm 1.21$ & $13.09 \pm 1.97$ & $2.37 \pm 0.50$ & \\
\hline Week 1 & $3.78 \pm 1.45$ & $17.05 \pm 2.32$ & $1.85 \pm 0.46$ & $<0.001$ \\
\hline Week 2 & $3.27 \pm 1.56$ & $18.18 \pm 2.37$ & $1.57 \pm 0.49$ & $<0.001$ \\
\hline Week 4 & $2.71 \pm 1.72$ & $18.87 \pm 2.39$ & $1.43 \pm 0.51$ & $<0.001$ \\
\hline Week 8 & $2.11 \pm 1.85$ & $19.62 \pm 2.49$ & $1.31 \pm 0.51$ & $<0.001$ \\
\hline Week 12 & $2.51 \pm 1.94$ & $19.31 \pm 2.75$ & $1.35 \pm 0.54$ & $<0.001$ \\
\hline Week 24 & $2.85 \pm 2.06$ & $18.85 \pm 2.90$ & $1.47 \pm 0.62$ & $<0.001$ \\
\hline Week 36 & $3.18 \pm 2.04$ & $18.53 \pm 3.00$ & $1.52 \pm 0.62$ & $<0.001$ \\
\hline Date are present as mean \pm standard deviation & \\
\hline
\end{tabular}




\section{Secondary outcomes}

There were significant between-group differences in the change from baseline to 36 weeks in ACQ- 5 score (difference in changes, -0.80 points [ $95 \% \mathrm{Cl},-1.00$ to -0.40 ]; $P<0.001$ ); ACT score (difference in changes, 3.00 points [95\% Cl, 2.00 to 4.00]; $P<0.001$ ); AQLQ score (difference in changes, 25.00 points [95\% $\mathrm{Cl}$, 14.00 to 34.00 ]; $P<0.001$ ); Rate of rescue medication used ( $36 \mathrm{w}, 5.0 \%$ vs. $29.1 \%, P=0.003$ ). The changes in these outcomes to prespecified endpoints are summarized in Table 2, Table 3, and Fig. 2. Adverse events were infrequent and generally not attributed to the intervention therapy (Table 2 and Table 5). A total of 11 A.E.s were judged to be mild. Intervention group: disturbances of glucose level $(2,5 \%)$; headache (1, 2.5\%). Control group: insomnia (3,5.5\%); drowsiness $(2,3.6 \%)$; anxiety $(1,1.8 \%)$; rash (1, $1.8 \%)$; palpitation $(1,1.8 \%)$. Two patients developed a transient disturbance of glucose level after latent MTrPs injection, and this phenomenon was disappeared within $30 \mathrm{~min}$.

Table 5

Adverse events in study participants

\begin{tabular}{|lll|}
\hline Adverse events, $\mathbf{n}(\%)$ & Intervention group $(\mathbf{n}=\mathbf{4 0})$ & Control group $(\mathbf{n}=\mathbf{5 5})$ \\
\hline Anxiety & $0(0)$ & $1(1.8)$ \\
\hline Rash & $0(0)$ & $1(1.8)$ \\
\hline Insomnia & $0(0)$ & $3(5.5)$ \\
\hline Headache & $1(2.5)$ & $0(0)$ \\
Drowsiness & $0(0)$ & $2(3.6)$ \\
Disturbances of glucose level & $2(5)$ & $0(0)$ \\
\hline Palpitation & $0(0)$ & $1(1.8)$ \\
\hline
\end{tabular}

\section{Discussion}

This study was the first trial to evaluate the efficacy and safety of latent MTrPs injection for CVA. The latent MTrPs injection therapy showed significant improvement in asthma symptoms at all time points, especially at weeks 8 and weeks 12 . Although budesonide-formoterol plus montelukast therapy is effective for CVA to some extent, a proportion of patients whose symptoms remain uncontrolled. This study also suggests that latent MTrPs injection therapy could address patient's over-reliance or poor adherence to maintenance treatment with an inhale of glucocorticoids. There are no serious adverse events attributable to latent MTrPs injection or budesonide-formoterol plus montelukast therapy; two patients reported a transient disturbance of glucose level after latent MTrPs injection treatment, but they are alleviated quickly. We consider that this phenomenon is probably related to an imbalance between sympathetic and parasympathetic nerves caused by needle stimulation.

\section{Relationship between CVA and Latent MTrPs}


The pathogenesis and pathological process of CVA have not been fully defined. Previous studies have shown that transient receptor potential vanilloid 1 (TRPV1) and endogenous neuropeptides are closely associated with CVA development(13-17). According to the theory of Simons, latent MTrPs are located in symptom-free areas and only provoke referred pain and autonomic phenomena when stimulated. Prior research has established that there are many inflammatory cytokines are expressed near $\operatorname{MTrPs}(18)$, including bradykinin $(B K)$, capsaicin, substances $\mathrm{P}(S P)$, a- tumor necrosis factor, serotonin, histamine, norepinephrine, and extracellular fluid; the fluid contains hydrogen ions, which can induce the release of calcitonin gene-related peptides (CGRP) via the motor nerve endings and muscle nociceptive receptors(19). Some endogenous substances such as $S P, C G R P, B K$ can not only activate TRPV1 directly but also phosphorylate the specific structure of TRPV1, reducing its threshold and sensitizing TRPV1(20, 21). The depolarization current generated by the activation of TRPV1 is transmitted through the vagus nerve into the coughing center of the solitary nucleus(22). The relief of CVA symptoms after latent MTrPs injection gave us two main assumptions of a possible interaction between the physiopathology of CVA and latent MTrPs: (1) restored sympathetic/parasympathetic balance and (2) the remission of neurogenic inflammations at MTrPs. Our treatment also found that latent MTrPs injection located in head and neck muscles got more relieved in cough symptoms than those in limbs or shoulder. The result can be explained by neuroanatomy.

\section{Relief CVA Symptoms through Latent MTrPs Injection}

Various neuropeptides released by neurogenic inflammation have different effects on CVA. The CGRP can dilate the blood vessels by acting on CGRP receptors in the airway blood vessels, causing congestion and edema of the airway mucosa(23). SP acts on the NK1 receptor, increasing the airway microvascular permeability and promoting the infiltration of plasma protein and inflammatory cells. In addition, $S P$ also has an intense stimulation on airway smooth muscle and induces AHR. Latent MTrPs injection therapy relieved the neurogenic inflammations at MTrP, reduced the production of endogenous peptides such as $S P$ and CGRP, and balanced the sympathetic/parasympathetic nerves, thus restored the function of the airway mucosal glands.

We also considered whether the improvements of symptoms were related to the drug used for injection. Lidocaine has been reported to have anti-inflammatory properties, including inhibiting histamine release from mast cells and reducing the release of leukotrienes(24). However, each drug has its half-life, and the maximum blood concentration will not exceed a week. In our study, the relief of cough lasted for several weeks. Consequently, we supposed that the observed clinical improvements in CVA were due to latent MTrPs rather than the effects of injected drugs.

\section{Relationship between Latent MTrPs Injection and Traditional Acupuncture}

Although there was a $76 \%$ overlap between acupoints referred to by traditional Chinese medicine and MTrPs(25), we consider them different. First, acupoints are located in specific positions on the meridian. On the contrary, latent MTrPs are hyperirritable spots, usually, within a taut band of skeletal muscle; point 
location is individualized and may vary from person to person. Second, traditional Chinese medicine acupoints have pathological attributes and physiological attributes, whereas trigger points only have pathological attributes. In addition, trigger points injection focus on inducing LTRs.

\section{Conclusions}

There are not many scientific studies establishing a clear relation between CVA and latent MTrPs. In our study, compared with budesonide-formoterol plus montelukast therapy, latent MTrPs injection therapy provided a long-acting, effective, short treatment course and safety methods for CVA. We inferred that the inflammatory of latent MTrPs might play an essential role in the pathogenesis of CVA. The potential mechanism may be that neurogenic inflammations at MTrPs disrupt the balance between sympathetic and parasympathetic nerves in the autonomic nervous system, result in airway smooth muscle contraction and airway hyper-responsiveness. Future studies will clarify the pathophysiological mechanism among inflammations at MTrPs, autonomic nervous system imbalanced, and CVA.

\section{Materials And Methods}

\section{Trial design}

The trial was an open-label randomized controlled trial comparing the effect of latent MTrPs injection therapy vs. budesonide-formoterol plus montelukast therapy in adult CVA patients. Signed informed consent was obtained from all participants. The trial took place at Qilu Hospital, Cheeloo College of Medicine of Shandong University, Jinan, China. This study was approved by the Human Research Ethics Committee of Qilu hospital (KYLL-202011-127) and registered in the Clinical Trial Registry Center (ChiCTR2100044079).

Before randomization, eligible patients entered a 2-week single-blind placebo run-in period. After the run-in period, a total of 110 patients were randomly assigned utilizing computer access to internet assignment in a 1:1.5 allocation ratio to undergo intervention or control group. Intervention group $(n=44)$ : latent MTrPs injection only once, sternocleidomastoid tender points, medial or lateral pterygoid muscle tender points, and so on. Control group ( $n=66)$ : twice-daily budesonide-formoterol (160 ug budesonide and 4.5 ug of formoterol) plus montelukast $10 \mathrm{mg}$ for eight weeks. If patients have long-term poor asthma control during the trial, they will be allowed to use asthma rescue medication. Rescue medication was Salbutamol Sulphate Aerosol (GLAXO WELLCOME, S.A.: 100ug/treatment via a metered-dose inhaler, maximum usage $400 \mu \mathrm{g} / \mathrm{d}$ as needed).

Patients were recruited from the respiratory department of Qilu Hospital of Shandong University. After treatment, 36 weeks of follow up were carried out.

\section{Patients}


Patients 18 years of age or older who had received a clinical diagnosis of CVA (Global Initiative for Asthma [GINA] 2018 criteria $(26,27))$ at least eight weeks. The other patient inclusion criteria are as follows: (1) $<75$ years old. (2) any sex or ethnicity. (3) All patients signed an informed consent. The exclusion criteria are as follows: (1) Cough is caused by other diseases. (2) Patients with a known hypersensitivity to lidocaine or vitamin $B_{12}$. (3) Comorbidity includes chronic lung, cardiovascular, kidney, neurologic, or another systemic disease. (4) History of drug abuse (including oral corticosteroid) in the last three weeks. (5) Smoking within six months. (6) Pregnancy.

\section{Procedures}

\section{Intervention group:}

\section{Latent MTrPs injection procedures}

Drugs used for latent MTrPs injection containing vitamin $\mathrm{B}_{12}$ (JinYao Corp, Tianjin City, China; $1 \mathrm{ml}: 1 \mathrm{mg}$ ), $2 \%$ lidocaine injection (ZhaoHui Corp, Shanghai City, China; $5 \mathrm{ml}: 200 \mathrm{mg}$ ), and compound betamethasone injection (MSD Merck Sharp \& Dohme AG, Switzerland; $1 \mathrm{ml}$ : $5 \mathrm{mg}$ betamethasone bipropionate and $2 \mathrm{mg}$ betamethasone bisodium phosphate) were diluted to $20 \mathrm{ml}$ with $0.9 \%$ saline for a single injection. The latent MTrPs injection was performed with needle $25(0.5 * 36 \mathrm{~mm})$ and a $20 \mathrm{ml}$ syringe (We Go Corp, Weihai City, China).

The latent MTrPs main found in sternocleidomastoid, medial or lateral pterygoid muscles, splenius, and the greater or lesser occipital nerve by palpation. But it was difficult to palpate when some trigger points were hidden in muscles, and the finical therapeutic effects depend on the accuracy of palpated points(28). The sign of accurate latent MTrPs is confirmed by the 'jump sign' as shown by the patient, which may include withdrawal of the head, wrinkling of the face (or forehead), or a verbal response or muscle local twitch response (LTRs) $(11,12)$. Latent MTrPs palpation and injection procedure were performed as Travell and Simons' "trigger point manual" recorded.

\section{Medial or Lateral Pterygoid Muscles}

Palpation was performed with progressive and sustained deep single-finger pressure on the skin's surface to identify the latent MTrPs in medial or lateral pterygoid muscles. The patients were instructed to remain seated and keep his head and shoulder fixed to enable maximum relaxation of the researched muscles(29). Once trigger points were determined, the thumb of the therapist's one hand remained in a fixed position on the skin, disinfecting the surrounding skin, making the patients keep his/her mouth open (prevent needle blocking in the temporomandibular joint), the other hand take the syringe and insert it into muscles, adjusting the depth of the needle, when the patients felt referred pain, it is indicated that the needle was inserted into the latent MTrPs, then injecting 3-5ml liquid drugs. There are many small blood vessels adjacent to muscles; it is necessary to withdraw before injection to avoid intravascular injection. The other side was injected using the same technique. 


\section{Sternocleidomastoid Muscles}

When palpating in sternocleidomastoid muscles, let the patient sit up with his/her head slightly inclined to one side, and the examiner pinched the muscle with his thumb and index finger to identify the latent MTrPs. The same technique injected the both side of sternocleidomastoid muscles.

\section{Splenius Capitis Muscles}

Let the patient seat with his/her arms crossed on the desk and his/her forehead fell on the forearm, identifying the trigger points by palpation. The injection technique is the same as the above, pressed the puncture points after injection to promote the better absorption of drugs. Palpation and injection procedures were performed by the same professor who had 20 years of experience.

\section{Control group:}

Budesonide and formoterol Fumarate Powder for Inhalation (AstraZeneca AB: 160ug budesonide and 4.5ug of formoterol per inhaler, one inhaler every 12 hours, maximum usage four inhalers/d as needed) plus montelukast (Merck Sharp \& Dohme Ltd: 10mg per night) for eight weeks.

\section{Outcomes}

The primary outcomes were changes in cough visual analog scale (VAS) scores from baseline to 1 week, 2 weeks, 4 weeks, 8 weeks, 12 weeks, 24weeks and 36 weeks after treatment; recurrence rate within 36 weeks. VAS is a validated summative cough variant asthma score ranging from 0 to 10 points, where VAS scores of 1-3, 4-6, and 7-10 points indicate mild, moderate, and severe asthma, respectively. The higher the score, the more serious the symptoms(30). VAS scores were divided into daytime cough scores and nighttime cough scores. Scores were assessed on a 6-point scale ranging from 0 to 5 , with higher values indicating more severe cough symptoms. VAS changes less than 2 points compared with the baseline, which is regarded as recurrence.

The secondary outcomes mainly included changes in the ACQ- 5 scores, ACT scores, AQLQ scores from baseline to 1 week, 2 weeks, 4 weeks, 8 weeks, 12 weeks, 24weeks and 36 weeks after treatment. The "Asthma Control Questionnaire" (ACQ) is a very common questionnaire for assessing asthma control. ACQ-5 includes five questions about the asthma symptoms of the previous week(31). Each scored ranged from 0 (no impairment) to 6 points (maximum impairment). The ACT also includes five questions about the asthma symptoms of the previous four weeks, each score ranging from 1 (max impairment) to 5 points (no impairment). The AQLQ contains twenty-seven questions about asthma symptoms and social and psychological problems during the previous 1 week. Each item is scored on a scale of 1 (severely impairment) to 7 points (no impairment). And the rate of rescue medication treatments administered within 36 weeks. Safety was evaluated according to the type and severity of adverse events (A.E.S). After latent MTrPs injection, there was a 30 minutes observation period. Patients were required to record any local or systemic effects during the follow-up period. 


\section{Statistical Analysis}

Used PASS Sample Size Software to estimate sample size. We calculated that 31 participants in the intervention group and 46 participants in the control group would provide the trial with at least $95 \%$ power (2-sided $\mathrm{a}=0.05$ ) to detect differences in the primary endpoint (VAS) between the two groups. We used the SPSS version 22.0 software and GraphPad Prism 8.3 for statistical analysis. Numerical results are presented as mean \pm standard deviation. The Mann-Whitney $U$ test was used to assess the difference between the two groups, and the paired Student's t-test was used to assess the difference from baseline to 36 weeks within each group. For categorical endpoints, dates were compared using either the chi-square test or Fisher's exact test. For continuous variables, the medians were compared with a MannWhitney $U$ test. Difference in medians were calculated using the Hodges-Lehmann estimate. A $P$ value less than 0.05 was considered to indicated statistical significance.

\section{Abbreviations}

CVA: Cough variant asthma

MTrPs: Myofascial trigger points

LTR: Local twitch responses

AHR: Airway hyper-responsiveness

VAS: Visual analog scale

ACT: Asthma control test

ACQ5: Asthma control questionnaire-5

AQLQ: Asthma quality of life questionnaire

TRPV1: Transient receptor potential vanilloid 1

SP: Substance P

CGRP: Calcitonin gene-related peptide

BK: bradykinin

NK1: Neurokinin 1

\section{Declarations}

Acknowledgments 
Authors would like to thank Prof. Hui Han (Center of Medical Quality Control and Hospital Infection, Qilu Hospital, Cheeloo College of Medicine, Shandong University, China) for his contributions to the investigation design.

\section{Author Contributions}

Qianqian Liu performed the statistical analysis and drafted the manuscript. Feng Qi designed the study and performed the latent MTrPs injection procedure. Tian Tian participated in patient's recruitment and guided the procedure of budesonide-formoterol combined montelukast therapy at the Department of Respiratory. Wenwen Zhang, He Bai, and Qiya Hu participated in patient's recruitment and follow up. All authors read and approved the final manuscript.

\section{Funding}

This study was funded in part by the National Natural Science Foundation of China (No. 81672250) and the Fundamental Research Funds of Shandong University.

\section{Conflict of Interest Disclosures}

The authors declare that the research was conducted in the absence of any commercial or financial relationships that could be construed as a potential conflict of interest.

\section{Availability of data and materials}

The datasets used and/or analyzed during the current study are available from the corresponding author on reasonable request.

\section{Ethics approval and consent to participate}

This study was approved by the Qilu Hospital, Cheeloo College of Medicine, Shandong University Human Research Ethics Committee (KYLL-202011-127) and registered with the Clinical Trial Registry Center (ChiCTR2100044079). All subjects received written informed consent information regarding their participation.

\section{Consent for publication}

All study participants have signed informed consent and agree to conduct research and publish research articles, the photos appearing in the article can't recognize the facial features of participants.

\section{Competing interests}

The authors declare that they have no competing interests.

\section{References}


1. Huang $\mathrm{K}$, Yang T, Xu J, Yang L, Zhao J, Zhang X, et al. Prevalence, risk factors, and management of asthma in China: a national cross-sectional study. Lancet. 2019;394(10196):407-18.

2. Lai K, Chen R, Lin J, Huang K, Shen $H$, Kong L, et al. A prospective, multicenter survey on causes of chronic cough in China. Chest. 2013;143(3):613-20.

3. Liu W, Chen H, Zhang D, Wu F, Zhou L. A retrospective study of clinical features of cough variant asthma in Chinese adults. Allergy Asthma Clin Immunol. 2019;15:3.

4. Cloutier MM, Dixon AE, Krishnan JA, Lemanske RF Jr, Pace W, Schatz M. Managing Asthma in Adolescents and Adults: 2020 Asthma Guideline Update From the National Asthma Education and Prevention Program. JAMA. 2020;324(22):2301-17.

5. Stanford RH, Shah MB, D'Souza AO, Dhamane AD, Schatz M. Short-acting beta-agonist use and its ability to predict future asthma-related outcomes. Ann Allergy Asthma Immunol. 2012;109(6):403-7.

6. Morice AH, Millqvist E, Bieksiene K, Birring SS, Dicpinigaitis P, Domingo Ribas C, et al. ERS guidelines on the diagnosis and treatment of chronic cough in adults and children. Eur Respir J. 2020;55(1).

7. Lima JJ. Do genetic polymorphisms alter patient response to inhaled bronchodilators? Expert Opin Drug Metab Toxicol. 2014;10(9):1231-40.

8. Bateman ED, Bousquet J, Busse WW, Clark TJ, Gul N, Gibbs M, et al. Stability of asthma control with regular treatment: an analysis of the Gaining Optimal Asthma controL (GOAL) study. Allergy. 2008;63(7):932-8.

9. Gerwin RD. Myofascial Trigger Point Pain Syndromes. Semin Neurol. 2016;36(5):469-73.

10. Turo D, Otto P, Shah JP, Heimur J, Gebreab T, Armstrong K, et al. Ultrasonic tissue characterization of the upper trapezius muscle in patients with myofascial pain syndrome. Annu Int Conf IEEE Eng Med Biol Soc. 2012;2012:4386-9.

11. Gerwin R. Trigger Point Diagnosis: At Last, the First Word on Consensus. Pain Med. 2018;19(1):1-2.

12. Bezerra Rocha CA, Sanchez TG, Tesseroli de Siqueira JT. Myofascial trigger point:a possible way of modulating tinnitus. Audiol Neurootol. 2008;13(3):153-60.

13. Smit LA, Kogevinas M, Anto JM, Bouzigon E, Gonzalez JR, Le Moual N, et al. Transient receptor potential genes, smoking, occupational exposures and cough in adults. Respir Res. 2012;13:26.

14. Kenyon NJ, Morrissey BM, Schivo M, Albertson TE. Occupational asthma. Clin Rev Allergy Immunol. 2012;43(1-2):3-13.

15. O'Byrne PM, Gauvreau GM, Brannan JD. Provoked models of asthma: what have we learnt? Clin Exp Allergy. 2009;39(2):181-92.

16. Watanabe N, Horie S, Michael GJ, Spina D, Page CP, Priestley JV. Immunohistochemical localization of vanilloid receptor subtype 1 (TRPV1) in the guinea pig respiratory system. Pulm Pharmacol Ther. 2005;18(3):187-97.

17. McGarvey LP, Butler CA, Stokesberry S, Polley L, McQuaid S, Abdullah H, et al. Increased expression of bronchial epithelial transient receptor potential vanilloid 1 channels in patients with severe asthma. J Allergy Clin Immunol. 2014;133(3):704-12. e4. 
18. Jin F, Guo Y, Wang Z, Badughaish A, Pan X, Zhang L, et al. The pathophysiological nature of sarcomeres in trigger points in patients with my ofascial pain syndrome: A preliminary study. Eur $\mathrm{J}$ Pain. 2020;24(10):1968-78.

19. Grosman-Rimon L, Parkinson W, Upadhye S, Clarke H, Katz J, Flannery J, et al. Circulating biomarkers in acute myofascial pain: A case-control study. Medicine. 2016;95(37):e4650.

20. Meents JE, Neeb L, Reuter U. TRPV1 in migraine pathophysiology. Trends Mol Med. 2010;16(4):1539.

21. Melnick C, Kaviany M. Thermal actuation in TRPV1: Role of embedded lipids and intracellular domains. J Theor Biol. 2018;444:38-49.

22. McMahon SB, La Russa F, Bennett DL. Crosstalk between the nociceptive and immune systems in host defence and disease. Nat Rev Neurosci. 2015;16(7):389-402.

23. Undem BJ, Taylor-Clark T. Mechanisms underlying the neuronal-based symptoms of allergy. J Allergy Clin Immunol. 2014;133(6):1521-34.

24. Morina N, Haliti A, lljazi A, Islami D, Bexheti S, Bozalija A, et al. Comparison of Effect of Leukotriene Biosynthesis Blockers and Inhibitors of Phosphodiesterase Enzyme in Patients with Bronchial Hyperreactivity. Open Access Maced J Med Sci. 2018;6(5):777-81.

25. Myofascial Meridians as Anatomical Evidence of Acupuncture Channels. \%J Medical Acupuncture. 2009;21(2):91-7.

26. "Global strategy for asthma management and prevention: GINA executive summary.". Bateman ED, Hurd SS, Barnes PJ, Bousquet J, Drazen JM, FitzGerald JM, Gibson P, Ohta K, O'Byrne P, Pedersen SE, Pizzichini E, Sullivan SD, Wenzel SE and H.J. Zar. Eur Respir J 2008; 31: 143-178. Eur Respir J. 2018;51(2).

27. Bateman ED, Reddel HK, O'Byrne PM, Barnes PJ, Zhong N, Keen C, et al. As-Needed BudesonideFormoterol versus Maintenance Budesonide in Mild Asthma. N Engl J Med. 2018;378(20):1877-87.

28. Alvarez DJ, Rockwell PG. Trigger points: diagnosis and management. Am Fam Physician. 2002;65(4):653-60.

29. Fernandez-de-Las-Penas C, Dommerholt J. International Consensus on Diagnostic Criteria and Clinical Considerations of Myofascial Trigger Points: A Delphi Study. Pain Med. 2018;19(1):142-50.

30. Miwa N, Nagano T, Ohnishi H, Nishiuma T, Takenaka K, Shirotani T, et al. An Open-Label, MultiInstitutional, Randomized Study to Evaluate the Additive Effect of a Leukotriene Receptor Antagonist on Cough Score in Patients with Cough-Variant Asthma Being Treated with Inhaled Corticosteroids. Kobe J Med Sci. 2018;64(4):E134-E9.

31. Werner CU, Linde K, Schaffner J, Storr C, Schneider A. Weekly self-measurement of FEV1 and PEF and its impact on ACQ (asthma control questionnaire)-scores: 12-week observational study with 76 patients. NPJ Prim Care Respir Med. 2017;27(1):64.

\section{Figures}




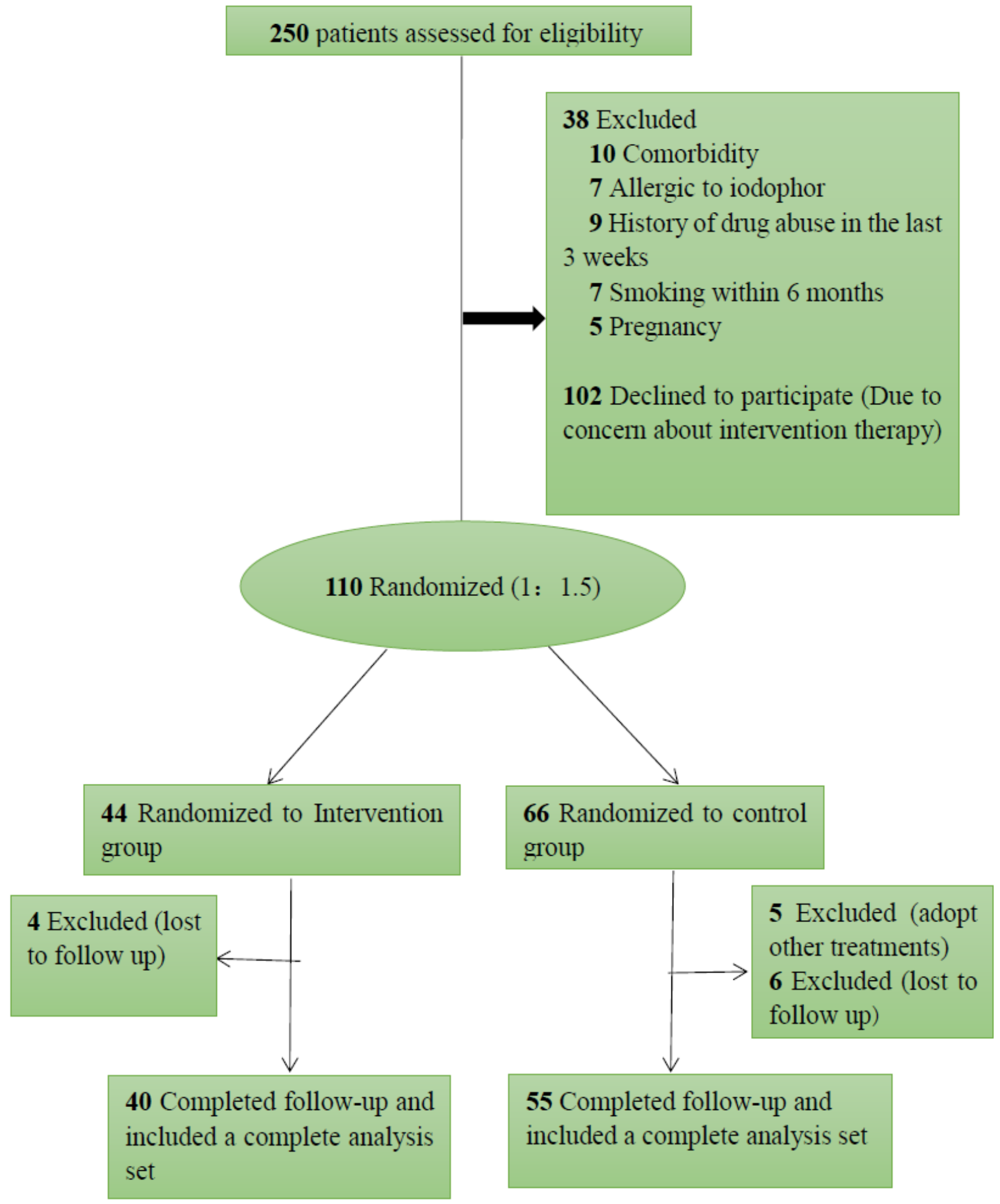

\section{Figure 1}

Flow diagram of trial procedure. 


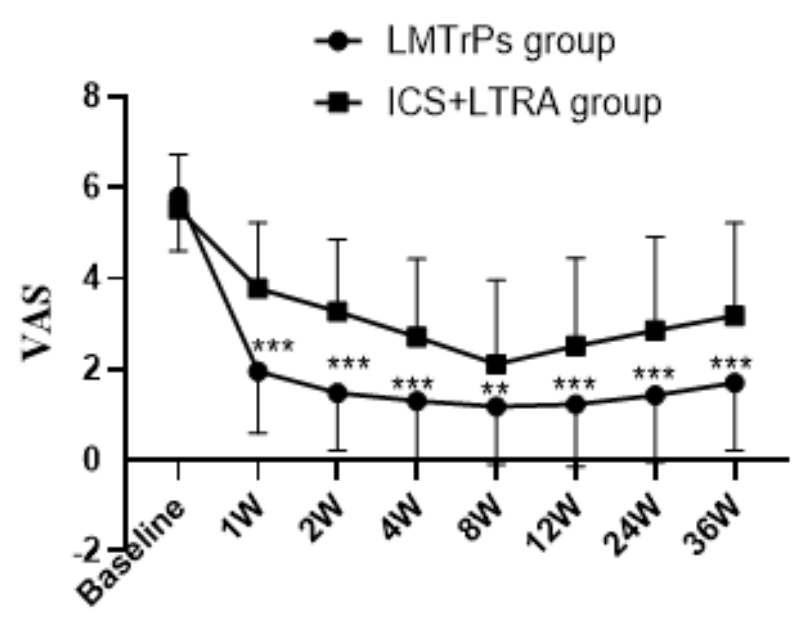

Times (W)

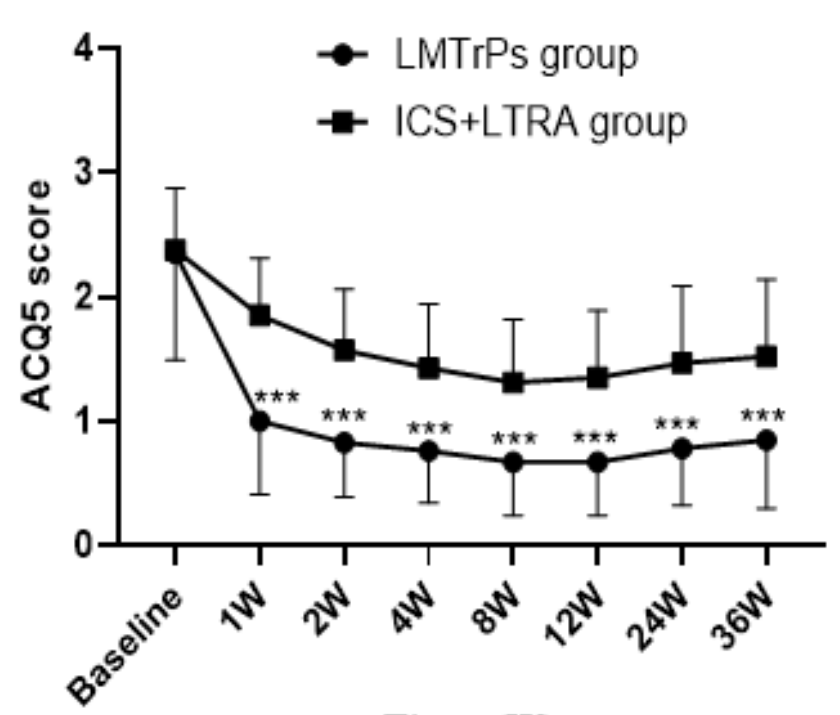

Times (W)

C
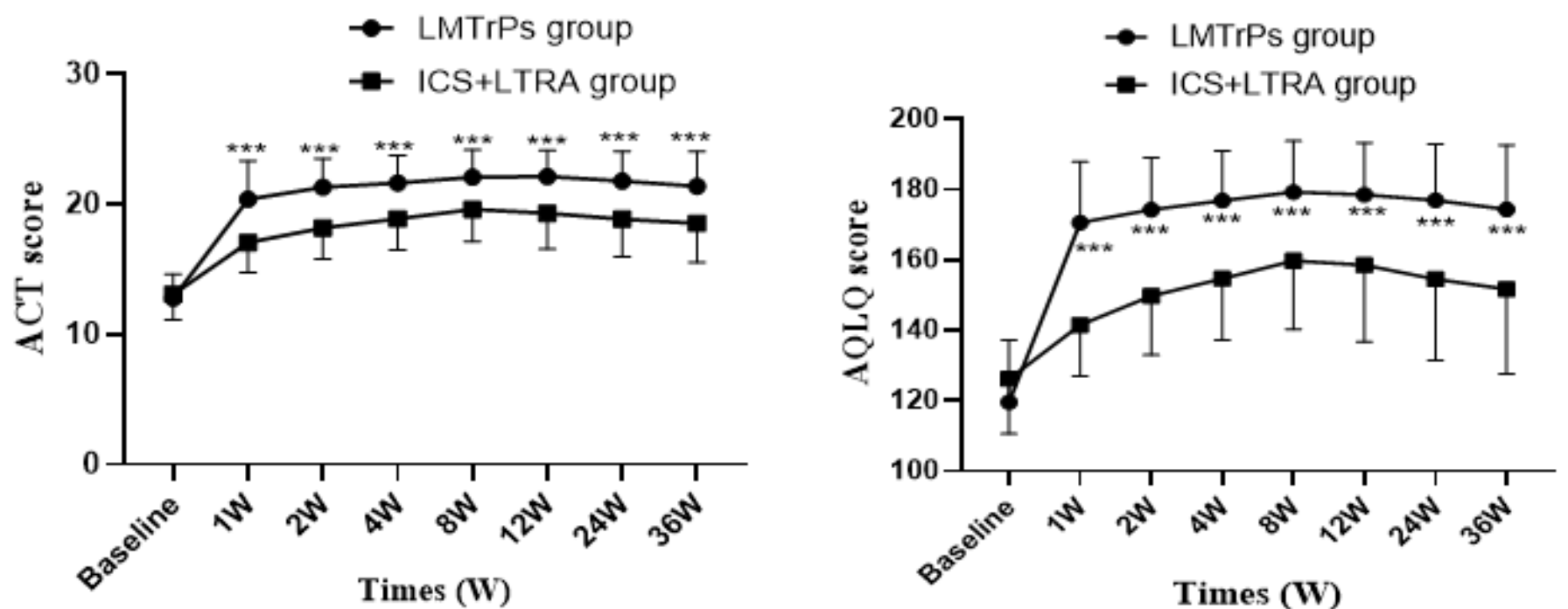

Figure 2

Change in VAS, ACQ5 scores, ACT scores and AQLQ scores according to time and group. Figures demonstrate values of VAS (A), ACQ5 score (B), ACT score (C) and AQLQ score (D) at each time point in intervention group and control group. ${ }^{*} P$ value $<0.05$; $* \star \star ~ P$ value $<0.001$, comparison between the two groups. 

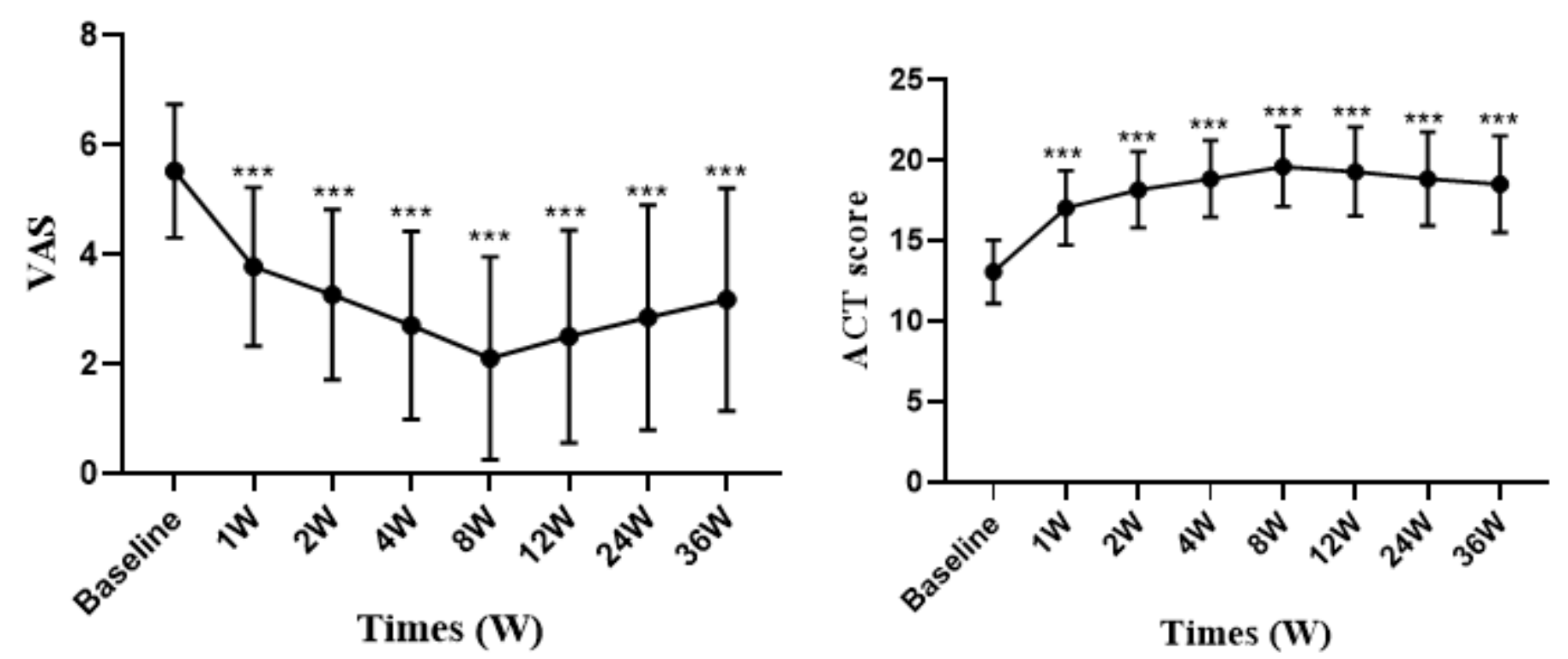

C

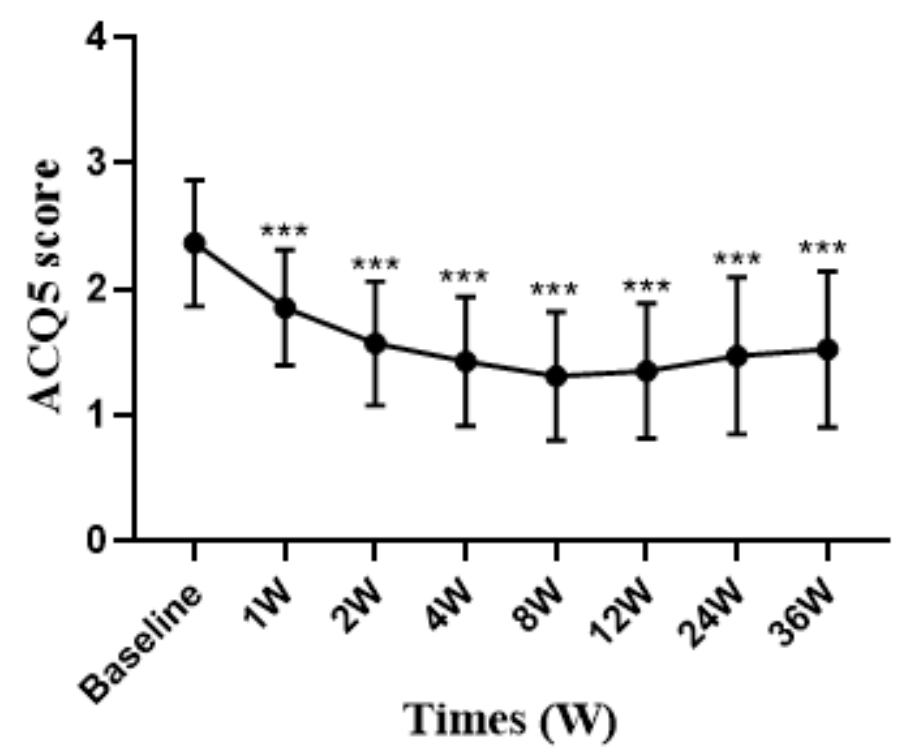

Figure 3

Change in VAS, ACT scores, ACQ5 scores according to times. Figures demonstrate values of VAS (A), ACT score (B) and ACQ5 score (C), at each time point in control group. * $P$ value $<0.05$; $\star \star \star ~ P$ value $<0.001$, compared to baseline. 